\title{
Efficacy and safety profile of once-weekly dulaglutide in type 2 diabetes: a report on the emerging new data
}

This article was published in the following Dove Press journal: Diabetes, Metabolic Syndrome and Obesity:Targets and Therapy

\author{
Anne J Kugler' \\ Michael L Thiman ${ }^{2}$ \\ 'Department of Pharmacy Practice \\ and Administration, Western \\ University of Health Sciences \\ College of Pharmacy, Pomona, CA, \\ USA; ${ }^{2}$ Department of Clinical and \\ Administrative Pharmacy, University \\ of Georgia College of Pharmacy, \\ Athens, GA, USA
}

\begin{abstract}
Dulaglutide is a once-weekly glucagon-like peptide-1 receptor agonist, which has been on the market in the USA since 2014. Dulaglutide has performed well in head-to-head studies against metformin, glargine, and sitagliptin, where its A1c lowering ranged from $-0.78 \%$ to $-1.64 \%$ over $52-104$ weeks, and it consistently outperformed each of these agents. As an add-on therapy, dulaglutide provided additional A1c lowering of $-1.4 \%$ to $-1.44 \%$ over monotherapy with glimepiride or glargine at 24 and 28 weeks, respectively. Dulaglutide outperformed exenatide when added to a regimen of metformin with pioglitazone as well as glargine when added to a regimen of metformin with glimepiride. Dulaglutide was shown to be non-inferior to liraglutide when added to metformin. In all AWARD studies other than when compared to liraglutide, dulaglutide at full strength resulted in significantly more patients achieving their A1c goal. Recent class-wide meta-analyses indicate that the incidence of commonly experienced gastrointestinal (GI) side effects is dose dependent, and nausea and vomiting are less common in longer-acting agents such as dulaglutide, but diarrhea may be more common. Pooled data have shown no increased risk of serious side effects such as pancreatitis or neoplasm with the use of dulaglutide. Given the evidence supporting liraglutide's cardiovascular benefits, the highly anticipated REWIND trial will have a significant impact on the future place in the therapy of dulaglutide.
\end{abstract}

Keywords: GLP-1 RA, glucagon-like peptide-1 receptor agonist, antidiabetic drugs, diabetes mellitus, injectable, incretin

\section{Introduction}

Glucagon-like peptide-1 (GLP-1) agonists act at GLP-1 receptors in pancreatic beta cells to increase intracellular cyclic AMP, which in turn increases glucose-dependent insulin secretion; in addition, they act to decrease glucagon release and slow gastric emptying. Dulaglutide (Trulicity ${ }^{\circledR}$; Eli Lilly and Company, Indianapolis, IN, USA) is a long-acting GLP-1 agonist that originally received US Food and Drug Administration (FDA) approval in 2014. The longer half-life of dulaglutide compared to earlier GLP-1 agonists is attributable to alterations that decrease DPP-IV hydrolysis as well as linkage to a constant fragment $\left(\mathrm{F}_{\mathrm{c}}\right)$ that increases protein size and decreases renal clearance. $^{1}$

Extensive Phase III study data have been published with regard to dulaglutide, much of which was part of the AWARD studies, which provide evidence for its use in combination with several other antidiabetic agents as well as direct comparisons to several antidiabetic drug classes. Previously published review articles have provided in-depth examinations of the earlier AWARD trials..$^{2-5}$ Since the approval of dulaglutide, several
Correspondence: Anne J Kugler Department of Pharmacy Practice and Administration, Western University of Health Sciences College of Pharmacy, 309 Second Street, Pomona, CA 91766-1854, USA

Tel +l 9094698637

Fax +I 9094695539

Email akugler@westernu.edu 
follow-up Phase III and Phase IV data have been published providing additional insights into clinical use of this agent. The purpose of this article is to review emerging clinical data pertaining to the efficacy and safety of dulaglutide in type 2 diabetes mellitus (T2DM).

\section{Literature search strategy}

A nonsystematic search was conducted on PubMed, Embase, and Cochrane Library using the following search terms: dulaglutide, LY2189265, Trulicity, glucagon-like peptide-1 receptor agonists (RAs), or GLP-1 RA. The limits imposed were English language, human studies, and original research, without any limitation of date range. Articles were filtered manually to remove duplicate studies, conference abstracts, and studies in patients without T2DM. To ensure completeness, bibliographies of relevant review articles and metaanalyses were also reviewed.

\section{Pharmacokinetics}

The maximum plasma concentration of dulaglutide is achieved at a median of 48 hours following subcutaneous administration, but a period of 2-4 weeks of weekly medication administration is needed to achieve steady state, which is not significantly impacted by the location of injection. Dulaglutide is broken down into its component amino acids by general protein catabolism pathways and is not impacted by the CYP450 isoenzymes or P-glycoprotein. The primary drug interactions of note involve concurrent use of antidiabetic medications such as insulin or sulfonylureas and increased risk of hypoglycemia. Elimination half-life for both the 0.75 and $1.5 \mathrm{mg}$ weekly doses is about 5 days. No dose adjustment is required for age, gender, race, ethnicity, body weight, or renal or hepatic impairment. ${ }^{6}$

\section{Mode of administration}

It is recommended to inject dulaglutide subcutaneously in the abdomen, thigh, or upper arm and to rotate the injection site. It is available as a single-dose pen containing $0.5 \mathrm{~mL}$ of solution, containing 0.75 or $1.5 \mathrm{mg}$ of active drug and equipped with a locking mechanism to prevent unintentional injection (Figure 1). No additional pen needle prescription is required, as a needle is already a part of the single-use device. No shaking or mixing is required, but the solution should be visually inspected for particulate matter and discoloration prior to administration. ${ }^{6} \mathrm{~A}$ medication guide is required to be dispensed with dulaglutide. ${ }^{7}$

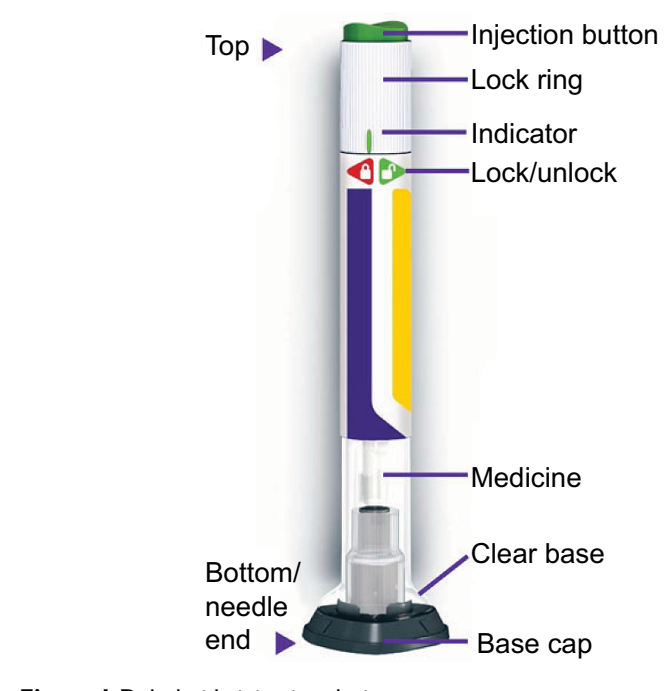

Figure I Dulaglutide injection device.

Note: Reproduced with permission Trulicity (dulaglutide) injection, solution [instructions for use] Indianapolis, IN: Eli Lilly and Company; 2016. Copyright @2016 Eli Lilly and Company. All Rights Reserved. ${ }^{47}$

\section{Review of Phase III trial data}

Within the AWARD study sequence, two trials compared dulaglutide to oral antidiabetic agents, specifically metformin (AWARD-3) and sitagliptin (AWARD-5). AWARD-3 was a 52-week study that randomized patients to dulaglutide (0.75 mg weekly), dulaglutide (1.5 mg weekly), or metformin (twice daily). Enrolled patients included those with baseline A1c values of $\geq 6.5 \%$ and $\leq 9.5 \%$ with only lifestyle management or a single, low-dose oral antidiabetic agent. Previous antidiabetic therapy was discontinued during the study lead-in period. Dulaglutide $(1.5 \mathrm{mg})$ demonstrated a significantly greater A1c reduction from a baseline of $7.6 \%$ compared to metformin at 52 weeks, with a significantly greater proportion of patients achieving A1c values of less than both $6.5 \%$ and $7 \%$ at the study end. No difference in serious adverse events (AEs) was noted, and only constipation was found to occur at a higher rate in the dulaglutide treatment groups compared to metformin. Weight loss was comparable between dulaglutide $(1.5 \mathrm{mg})$ and metformin. ${ }^{8}$ Details of efficacy parameters in AWARD trials are summarized in Table 1, and select safety end points are detailed in Table 2. AWARD-5 was a 104-week study that randomized patients receiving metformin to either dulaglutide ( $0.75 \mathrm{mg}$ weekly), dulaglutide (1.5 mg weekly), or sitagliptin (100 mg daily). Patients were eligible for enrollment if they were managed with lifestyle modification only and had baseline A1c values of $>8 \%$ and $\leq 9.5 \%$ or were managed on two or fewer oral antidiabetic agents with baseline A1c values of $\geq 7 \%$ and $\leq 9.5 \%$. At study conclusion, both doses of dulaglutide demonstrated significant $\mathrm{A} 1 \mathrm{c}$ reduction from baseline 
Table I Summary of select efficacy parameters in the AWARD study sequence

\begin{tabular}{|c|c|c|c|}
\hline Study design & tudy arms & Change in Alc & Alc $<7 \%$ \\
\hline $\begin{array}{l}\text { A 52-week study of } 978 \text { T2DM } \\
\text { patients (26-week primary end } \\
\text { point; AWARD-I)" }\end{array}$ & $\begin{array}{l}\text { DUL I.5 mg QW; DUL } 0.75 \mathrm{mg} \\
\text { QW; EXEN } 10 \mu \mathrm{gg} \text { BID; or } \\
\text { placebo (all received MET + } \\
\text { pioglitazone) }\end{array}$ & $\begin{array}{l}\text { DUL I.5 mg QW: }-1.5 \mathrm{I} \pm 0.06 \% \text {;a,b DUL } \\
0.75 \mathrm{mg} \text { QW: }-1.30 \pm 0.06 \% ; \text {;a, } \text { EXEN } 10 \mu \mathrm{g} \\
\text { BID: }-0.99 \pm 0.06 \% ; \text {; placebo: }-0.46 \pm 0.08 \%\end{array}$ & $\begin{array}{l}\text { DUL I.5 mg QW: 78\%;a,b DUL } \\
0.75 \text { mg QW: } 66 \% \text {;,b EXEN } \\
10 \mu \text { g BID: } 52 \% \text {; }^{\text {a }} \text { placebo: } 43 \%\end{array}$ \\
\hline $\begin{array}{l}\text { A 78-week study of } 810 \text { T2DM } \\
\text { patients (52-week primary end } \\
\text { point; AWARD-2) }\end{array}$ & $\begin{array}{l}\text { DUL I.5 mg QW; DUL } 0.75 \text { mg } \\
\text { QW; or GLAR daily (all received } \\
\text { MET + glimepiride) }\end{array}$ & $\begin{array}{l}\text { DUL I.5 mg QW: }-1.08 \pm 0.06 \% ; \mathrm{c} \text { DUL } \\
0.75 \mathrm{mg} \text { QW: }-0.76 \pm 0.06 \%{ }^{\mathrm{d}} \text { GLAR daily: } \\
-0.63 \pm 0.06 \%\end{array}$ & $\begin{array}{l}\text { DUL I.5 mg QW: } 53.2 \% \text {;e DUL } \\
0.75 \text { mg QW: } 37.1 \% \text {; GLAR daily: } \\
30.9 \%\end{array}$ \\
\hline $\begin{array}{l}\text { A 52-week study of } 807 \text { T2DM } \\
\text { patients (26-week primary end } \\
\text { point; AWARD-3) }\end{array}$ & $\begin{array}{l}\text { DUL } 1.5 \mathrm{mg} \text { QW; DUL } 0.75 \mathrm{mg} \\
\text { QW; or MET BID }\end{array}$ & $\begin{array}{l}\text { DUL I.5 mg QW: }-0.78 \pm 0.06 \% ;{ }^{f} \text { DUL } \\
0.75 \mathrm{mg} \text { QW: }-0.7 \mathrm{I} \pm 0.06 \% ;{ }^{f} \text { MET BID: } \\
-0.56 \pm 0.06 \%\end{array}$ & $\begin{array}{l}\text { DUL I.5 mg QW: } 62 \% ; 8 \text { DUL } \\
0.75 \text { mg QW: } 63 \% ; 8 \text { MET BID: } \\
54 \%\end{array}$ \\
\hline $\begin{array}{l}\text { A 52-week, open-label study of } \\
884 \text { T2DM patients } \\
\text { (26-week primary end point; } \\
\text { AWARD-4) }\end{array}$ & $\begin{array}{l}\text { DUL I.5 mg QW; DUL } 0.75 \text { mg } \\
\text { QW; or GLAR QHS (all received } \\
\text { insulin lispro) }\end{array}$ & $\begin{array}{l}\text { DUL I.5 mg QW: -I.64\%;,e, DUL } 0.75 \mathrm{mg} \\
\text { QW: - I.59\%;,h GLAR QHS: - I.41\% }\end{array}$ & $\begin{array}{l}\text { DUL } 1.5 \text { mg QW: } 68 \% ;{ }^{e} \text { DUL } \\
0.75 \text { mg QW: } 69 \% \text {; GLAR QHS: } \\
57 \%\end{array}$ \\
\hline $\begin{array}{l}\text { A 104-week study of } 1098 \\
\text { T2DM patients } \\
\text { (52-week primary end point; } \\
\text { AWARD-5) }\end{array}$ & $\begin{array}{l}\text { DUL I.5 mg QW; DUL } 0.75 \mathrm{mg} \\
\text { QW; or SIT } 100 \mathrm{mg} \text { daily }\end{array}$ & $\begin{array}{l}\text { DUL I.5 mg QW: }-I .10 \pm 0.06 \% ; \text { DUL } \\
0.75 \text { mg QW: }-0.87 \pm 0.06 \% ; \text { SIT I00 mg } \\
\text { daily: }-0.39 \pm 0.06 \%\end{array}$ & $\begin{array}{l}\text { DUL I.5 mg QW: } 58 \% ; \text { ' DUL } \\
0.75 \text { mg QW: } 49 \% ; \text { SIT } 100 \mathrm{mg} \\
\text { daily: } 33 \%\end{array}$ \\
\hline $\begin{array}{l}\text { A } 26 \text {-week, open-label } \\
\text { study of } 599 \text { T2DM patients } \\
(\text { AWARD-6) }\end{array}$ & $\begin{array}{l}\text { DUL I.5 mg QW or LIR } 1.8 \mathrm{mg} \\
\text { daily (all received MET) }\end{array}$ & $\begin{array}{l}\text { DUL I.5 mg QW: }-1.42 \pm 0.05 \% ; \text { ' LIR I.8 mg } \\
\text { daily: }-1.36 \pm 0.05 \%\end{array}$ & $\begin{array}{l}\text { DUL } 1.5 \text { mg QW: } 68 \% \text {; LIR } \\
\text { I.8 mg daily: } 68 \%\end{array}$ \\
\hline $\begin{array}{l}\text { A 24-week study of } 300 \text { T2DM } \\
\text { patients (AWARD-8) }\end{array}$ & $\begin{array}{l}\text { DUL I.5 mg QW or placebo (all } \\
\text { received glimepiride) }\end{array}$ & DUL I.5 mg QW: -I.4\%;, placebo: -0.1\%;" & $\begin{array}{l}\text { DUL I.5 mg QW: } 55.3 \% ;{ }^{a} \\
\text { placebo: } 18.9 \%\end{array}$ \\
\hline $\begin{array}{l}\text { A 28-week study of } 300 \text { T2DM } \\
\text { patients (AWARD-9) }{ }^{17}\end{array}$ & $\begin{array}{l}\text { DUL I.5 mg QW or placebo (all } \\
\text { received GLAR) }\end{array}$ & $\begin{array}{l}\text { DUL I.5 mg QW: }-1.44 \pm 0.09 \% ;{ }^{a} \text { placebo: } \\
-0.67 \pm 0.09 \%\end{array}$ & $\begin{array}{l}\text { DUL I.5 mg QW: } 66.7 \%{ }^{a} \\
\text { placebo: } 33.3 \%\end{array}$ \\
\hline
\end{tabular}

Notes: ${ }^{\text {aSignificant vs placebo. }{ }^{b} \text { Significant vs exenatide. 'Superior vs glargine. }{ }^{\mathrm{N}} \text { Non-inferior vs glargine. é }}$ Significant vs glargine. 'Superior vs metformin. ${ }^{8}$ Significant vs metformin. "Standard error values not reported. 'Significant vs sitagliptin. 'Non-inferior vs liraglutide.

Abbreviations: AWARD, Assessment of Weekly AdministRation of LY2189265 (dulaglutide) in Diabetes; BID, twice daily; DUL, dulaglutide; EXEN, exenatide; GLAR, glargine; LIR, liraglutide; MET, metformin; QHS, at bedtime; QW, once weekly; SIT, sitagliptin; T2DM, type 2 diabetes mellitus.

compared to sitagliptin with significantly greater proportions of patients assigned to either dulaglutide dose achieving A1c values of $<7 \%$ and $\leq 6.5 \%$. Significantly greater weight loss was seen in the dulaglutide $1.5 \mathrm{mg}$ group compared to sitagliptin. A greater incidence of gastrointestinal (GI) AEs was seen in both dulaglutide groups when compared to sitagliptin. ${ }^{9}$ Similar significant improvements in glycemic control were demonstrated in an open-label, nonrandomized study conducted in a Japanese patient population that examined the addition of dulaglutide ( $0.75 \mathrm{mg}$ weekly) to single-agent oral antidiabetic therapy. For inclusion, patients could be maintained on single-agent therapy with either a sulfonylurea, biguanide, alpha-glucosidase inhibitor, thiazolidinedione, or meglitinide. A1c reduction from baseline was significant in all groups and varied from $-1.57 \%$ to $-1.69 \% .^{10}$

Both the AWARD-1 and AWARD-6 studies compared dulaglutide to alternative GLP-1 agonists, exenatide and liraglutide, respectively. AWARD-1 was a 52-week, parallel-arm study that compared multiple doses of dulaglutide to exenatide when added to pioglitazone and metformin background therapy in patients with a mean A1c value of $8.1 \%$ at baseline. Patients were randomized to one of four treatment groups including dulaglutide (1.5 or $0.75 \mathrm{mg}$ once weekly), exenatide (10 $\mu \mathrm{g}$ twice daily), or placebo. Both doses of dulaglutide demonstrated significantly greater reductions in A1c at 52 weeks compared to exenatide with a significantly greater proportion of patients achieving A $1 \mathrm{c}$ values $<7 \%$ and $<6.5 \%$ at study conclusion. The lower dulaglutide dose demonstrated significantly fewer total GI AEs compared to exenatide while the higher dulaglutide dose was not significantly different when compared to exenatide. ${ }^{11}$ AWARD-6 was a 26-week, open-label, non-inferiority study that randomized patients with $A 1 c$ values of $\geq 7 \%$ and $\leq 10 \%$ while receiving at least $1500 \mathrm{mg}$ of metformin daily to dulaglutide (1.5 mg weekly) or liraglutide (1.8 mg daily). The mean baseline A1c value in both groups was $8.1 \%$. Dulaglutide was found to be non-inferior to liraglutide with regard to A1c reduction from baseline. A greater reduction in body weight was demonstrated in the liraglutide group compared to dulaglutide. No significant differences were noted in treatment-emergent AEs. ${ }^{12}$ An additional Phase III study in a Japanese patient population lends further data to the comparison of dulaglutide with alternative GLP-1 agonists. In patients randomized to either dulaglutide ( $0.75 \mathrm{mg}$ weekly) or liraglutide ( $0.9 \mathrm{mg}$ daily), a significantly greater A1c reduction was seen in the dulaglutide arm. ${ }^{13}$ 
Table 2 Summary of select safety parameters in the AWARD study sequence

\begin{tabular}{|c|c|c|c|c|}
\hline Study & Nausea & $\begin{array}{l}\text { Systolic BP change from } \\
\text { baseline }(\mathrm{mmHg})\end{array}$ & $\begin{array}{l}\text { HR change from baseline } \\
\text { (bpm) }\end{array}$ & Discontinuation due to $\mathrm{AE}$ \\
\hline $\begin{array}{l}\text { AWARD-I" } \\
\text { (26-week primary } \\
\text { end point) }\end{array}$ & $\begin{array}{l}\text { DUL I.5 mg QW: 28\%;a } \\
\text { DUL } 0.75 \text { mg QW: } \\
\text { I6\%;,ab EXEN } 10 \mu g \text { BID: } \\
26 \% ;{ }^{\text {a }} \text { placebo: } 6 \%\end{array}$ & $\begin{array}{l}\text { DUL I.5 mg QW: } 0.1 \mathrm{I} \pm 0.83 ;{ }^{\mathrm{a}} \\
\text { DUL } 0.75 \mathrm{mg} \text { QW: } \\
-0.36 \pm 0.82 ;{ }^{\mathrm{a}} \text { EXEN } 10 \mu \mathrm{g} \text { BID: } \\
0.06 \pm 0.83 \text {; }^{2} \text { placebo: } 3.40 \pm \mathrm{I} .13\end{array}$ & $\begin{array}{l}\text { DUL I.5 mg QW: } 2.80 \pm 0.52 ; a, b \\
\text { DUL } 0.75 \text { mg QW: } \\
2.80 \pm 0.5 \mathrm{I} ; \mathrm{a}, \mathrm{b} \text { EXEN } 10 \mu \mathrm{g} \text { BID: } \\
\text { I.18 } 0.52 \text {; placebo: } 0.6 \mathrm{I} \pm 0.70\end{array}$ & $\begin{array}{l}\text { DUL I.5 mg QW: 3\%; DUL } \\
0.75 \text { mg QW: I\%; EXEN } 10 \mu g \\
\text { BID: } 3 \% \text {; placebo: } 2 \%\end{array}$ \\
\hline $\begin{array}{l}\text { AWARD-2 }{ }^{14} \\
\text { (52-week primary } \\
\text { end point) }\end{array}$ & $\begin{array}{l}\text { DUL I.5 mg QW: } \\
\text { I4.3\%;" DUL } 0.75 \text { mg } \\
\text { QW: 6.6\%;" GLAR daily: } \\
\text { I.5\% }\end{array}$ & $\begin{array}{l}\text { DUL I.5 mg QW: } 0.17 \pm 0.8 \mathrm{I} \\
\text { DUL } 0.75 \mathrm{mg} \text { QW: } 0.09 \pm 0.80 \\
\text { GLAR daily: } 0.5 \mathrm{I} \pm 0.83\end{array}$ & $\begin{array}{l}\text { DUL I.5 mg QW: I. } 29 \pm 0.50 ; \\
\text { DUL } 0.75 \text { mg QW: } 0.5 \mathrm{I} \pm 0.49 \\
\text { GLAR daily: }-0.52 \pm 0.5 \mathrm{I}\end{array}$ & $\begin{array}{l}\text { DUL I.5 mg QW: } 2.9 \% \text {; DUL } \\
0.75 \text { mg QW: } 2.6 \% \text {; GLAR daily: } \\
\text { I.5\% }\end{array}$ \\
\hline $\begin{array}{l}\text { AWARD- } 3^{8} \\
\text { (26-week primary } \\
\text { end point) }\end{array}$ & $\begin{array}{l}\text { DUL I.5 mg QW: I9\%; } \\
\text { DUL } 0.75 \text { mg QW: } \\
\text { I0.7\%; MET BID: } 14.6 \%\end{array}$ & $\begin{array}{l}\text { DUL I.5 mg QW: }-1.9 \pm 0.89 \\
\text { DUL } 0.75 \text { mg QW: }-2.6 \pm 0.88 \\
\text { MET BID: }-0.9 \pm 0.89\end{array}$ & $\begin{array}{l}\text { DUL I.5 mg QW: } 2.4 \pm 0.58 \text {; } \\
\text { DUL } 0.75 \text { mg QW: } 2.1 \pm 0.57 \text {; } \\
\text { MET BID: } 1.6 \pm 0.58\end{array}$ & $\begin{array}{l}\text { DUL I.5 mg QW: } 4.8 \% \text {; DUL } \\
0.75 \text { mg QW: 2.2\%; MET BID: } \\
3.7 \%\end{array}$ \\
\hline AWARD-4 ${ }^{15}$ & DUL I.5 mg QW: 26\%; & DUL I.5 mg QW: $-0.26 ;$ DUL & DUL 1.5 mg QW: 2.38;,,d DUL & DUL 1.5 mg QW: I I\%; DUL \\
\hline $\begin{array}{l}\text { (26-week primary } \\
\text { end point) }\end{array}$ & $\begin{array}{l}\text { DUL } 0.75 \text { mg QW: } \\
\text { I8\%; GLAR QHS: 3\% }\end{array}$ & $\begin{array}{l}0.75 \mathrm{mg} \text { QW: } 1.04 ;{ }^{d} \text { GLAR } \\
\text { QHS: } 1.98^{d}\end{array}$ & $\begin{array}{l}0.75 \mathrm{mg} \text { QW: } 2.27 \text {; GLAR } \\
\text { QHS: } 0.93^{\mathrm{d}}\end{array}$ & $\begin{array}{l}0.75 \text { mg QW: 8\%; GLAR QHS: } \\
4 \%\end{array}$ \\
\hline $\begin{array}{l}\text { AWARD-59 } \\
\text { (52-week primary } \\
\text { end point) }\end{array}$ & $\begin{array}{l}\text { DUL I.5 mg QW: I7\%;e } \\
\text { DUL } 0.75 \text { mg QW: } \\
\text { I3\%; SIT I00 mg daily: } \\
4 \%\end{array}$ & $\begin{array}{l}\text { DUL I.5 mg QW: }-0.8 \pm 0.7 \\
\text { DUL } 0.75 \text { mg QW: }-0.5 \pm 0.7 \\
\text { SIT I00 mg daily: }-0.5 \pm 0.7\end{array}$ & $\begin{array}{l}\text { DUL I.5 mg QW: } 2.4 \pm 0.5 ; \\
\text { DUL } 0.75 \text { mg QW: } 2.1 \pm 0.5 ; \\
\text { SIT I00 mg daily: }-0.3 \pm 0.5\end{array}$ & $\begin{array}{l}\text { DUL I.5 mg QW: II\%; DUL } \\
0.75 \text { mg QW: 8\%; SIT I00 mg } \\
\text { daily: 10\% }\end{array}$ \\
\hline AWARD-6 $6^{12}$ & $\begin{array}{l}\text { DUL I.5 mg QW: } 20 \% \text {; } \\
\text { LIR I.8 mg daily: } 18 \%\end{array}$ & $\begin{array}{l}\text { DUL I.5 mg QW: }-3.36 \pm 0.7 \\
\text { LIR I.8 mg daily: }-2.82 \pm 0.7\end{array}$ & $\begin{array}{l}\text { DUL I.5 mg QW: } 2.37 \pm 0.4 ; \\
\text { LIR I.8 mg daily: } 3.12 \pm 0.4\end{array}$ & $\begin{array}{l}\text { DUL I.5 mg QW: } 6 \% \text {; LIR } \\
\text { I.8 mg daily: } 6 \%\end{array}$ \\
\hline AWARD-8 $8^{18}$ & $\begin{array}{l}\text { DUL I.5 mg QW: } \\
\text { 10.5\%; }{ }^{\mathrm{a}} \text { placebo: } 0 \%\end{array}$ & $\begin{array}{l}\text { DUL I. } 5 \mathrm{mg} \text { QW: }-0.52 \pm 0.96 \\
\text { placebo: } 0.00 \pm 1.54\end{array}$ & $\begin{array}{l}\text { DUL I.5 mg QW: } 2.92 \pm 0.67{ }^{a} \\
\text { placebo: } 0.30 \pm 1.09\end{array}$ & $\begin{array}{l}\text { DUL } 1.5 \mathrm{mg} \text { QW: } 4.2 \% \text {; } \\
\text { placebo: } 0 \%\end{array}$ \\
\hline AWARD-917 & $\begin{array}{l}\text { DUL I.5 mg QW: } \\
\text { I2.0\%; placebo: } 1.3 \%\end{array}$ & $-f$ & $-f$ & $\begin{array}{l}\text { DUL I.5 mg QW: 4\%; placebo: } \\
\text { I.3\% }\end{array}$ \\
\hline
\end{tabular}

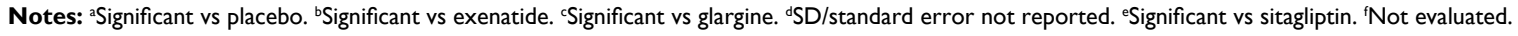

Abbreviations: AE, adverse event; AWARD, Assessment of Weekly AdministRation of LY2189265 (dulaglutide) in Diabetes; BID, twice daily; BP, blood pressure; DUL, dulaglutide; EXEN, exenatide; GLAR, glargine; HR, heart rate; LIR, liraglutide; MET, metformin; QHS, at bedtime; QW, once weekly; SIT, sitagliptin.

Several AWARD studies have compared dulaglutide to basal insulin, specifically insulin glargine. The AWARD-2 study was a 78-week, open-label, non-inferiority trial that included patients with A1c values of $\geq 7 \%$ and $\leq 11 \%$ while maintained on one to three oral antidiabetic medications. Patients were randomized to treatment with dulaglutide ( $0.75 \mathrm{mg}$ weekly), dulaglutide (1.5 $\mathrm{mg}$ weekly), or insulin glargine, and all patients received metformin and glimepiride background therapy. Insulin glargine was adjusted using a standardized titration algorithm. A1c reduction with dulaglutide $(0.75 \mathrm{mg})$ was found to be non-inferior to insulin glargine, and dulaglutide $(1.5 \mathrm{mg})$ was found to be superior to insulin glargine at week 52. A significantly greater proportion of patients receiving dulaglutide $(1.5 \mathrm{mg})$ achieved an A1c value of $<7.0 \%$ at week 52 compared to insulin glargine, while both dulaglutide doses demonstrated a significantly greater proportion of patients achieving an A1c value of $\leq 6.5 \%$ at the same time point. Both dulaglutide doses were associated with weight loss, while insulin glargine demonstrated weight gain; this difference was found to be significant. GI AEs were more common in both dulaglutide groups when compared to insulin glargine; however, serious
AEs were comparable across treatment groups. ${ }^{14}$ AWARD-4 was a 52-week, open-label, non-inferiority trial that enrolled patients with A1c values of $\geq 7 \%$ and $\leq 11 \%$ while receiving $1-2$ doses of insulin per day. Participants were randomized to treatment with dulaglutide ( $0.75 \mathrm{mg}$ weekly), dulaglutide (1.5 mg weekly), or insulin glargine, with all patients receiving insulin lispro. Patients were permitted to be maintained on metformin during the study; however, no other oral agents were allowed. Dulaglutide (both 0.75 and $1.5 \mathrm{mg}$ ) demonstrated significantly greater A1c reduction compared to insulin glargine, although it is noteworthy that significantly greater doses of insulin lispro were utilized in both dulaglutide treatment groups. At study conclusion, dulaglutide $(1.5 \mathrm{mg})$ resulted in a greater proportion of patients achieving an A1c value of $<7 \%$ compared to insulin glargine, and there were no differences between treatment groups in the proportion of patients achieving an A1c value of $\leq 6.5 \%$. Fewer serious AEs occurred in the dulaglutide $1.5 \mathrm{mg}$ group compared to insulin glargine, but GI AEs were more likely in both dulaglutide groups compared to insulin glargine. ${ }^{15}$ These results are further supported by an additional Phase III study conducted in a Japanese patient population com- 
paring dulaglutide to insulin glargine in patients maintained on sulfonylurea and/or biguanide. In this patient population, dulaglutide demonstrated a significantly greater A1c reduction compared to insulin glargine. ${ }^{16}$

A recently published study (AWARD-9) provides additional data for the use of dulaglutide in combination with insulin therapy in patients with T2DM. AWARD-9 was a 28-week, parallel-arm study that randomized patients receiving titrated insulin glargine to either dulaglutide $(1.5 \mathrm{mg}$ weekly) or placebo. Patients with Alc values of $\geq 7 \%$ and $\leq 10.5 \%$ who were maintained on a stable dose of insulin glargine were eligible for enrollment. In addition, patients could be maintained on metformin therapy; however, this was not a requirement for inclusion. At baseline, patients' average age was $\sim 60$ years, study groups were $56.7 \%-58.7 \%$ male, average body mass index (BMI) was $\sim 33 \mathrm{~kg} / \mathrm{m}^{2}$, and an average A1c value was $8.3 \%-8.4 \%$. A significantly larger reduction in A1c was seen with dulaglutide $(-1.44 \%)$ compared to placebo $(-0.67 \%), p<0.001$. More than $66 \%$ of dulaglutide patients achieved an A1c value of $<7.0 \%$ compared to $33.3 \%$ of placebo patients, $p<0.001$, and $50 \%$ of dulaglutide patients reached an A $1 \mathrm{c}$ value of $\leq 6.5 \%$ compared to $16.7 \%$ of patients assigned to placebo, $p<0.001$. Dulaglutide demonstrated a significant reduction in weight from baseline $(-1.91 \mathrm{~kg})$ and resulted in a $-2.41 \mathrm{~kg}$ difference compared to placebo, $p<0.001$. A greater number of treatment-emergent AEs were seen in the dulaglutide treatment group compared to placebo, with a significantly greater incidence of GI AEs and decreased appetite. A significant difference in serious AEs was not demonstrated. ${ }^{17}$

An additional, more recently published study (AWARD-8) evaluated the impact of adding dulaglutide to background sulfonylurea therapy. This was a 24-week, parallel-arm study that randomized patients maintained on glimepiride to dulaglutide (1.5 mg weekly) or placebo. Patients with A1c values of $\geq 7.5 \%$ and $\leq 9.5 \%$ maintained on a consistent sulfonylurea dose were eligible for enrollment. At baseline, patients' average age was $\sim 58$ years, study groups were $53.3 \%-56.5 \%$ female, average BMI was $30.9-32.4 \mathrm{~kg} / \mathrm{m}^{2}$, and average A1c value was $8.4 \%$. Dulaglutide demonstrated a significantly greater reduction in A1c compared to placebo resulting in a $-1.3 \%$ treatment difference, $p<0.001$. By the study end, a greater proportion of dulaglutide patients achieved A1c values of $<7 \%$ and $\leq 6.5 \%, 55.3 \%$, and $40 \%$, respectively, compared to placebo patients, $18.9 \%$ and $9.4 \%$, respectively, $p<0.001$ for both comparisons. There was no significant difference in body weight change between groups at study conclusion. Treatment-emergent AEs were comparable between groups; however, a greater incidence in GI AEs was noted in the dulaglutide group compared to placebo. Both total hypoglycemia and symptomatic hypoglycemia were significantly more frequent in those receiving dulaglutide, $p<0.05 .^{18}$

\section{Cardiovascular (CV) impact}

A comprehensive meta-analysis of GLP-1 RAs was conducted to investigate the potential impact of these agents on mortality and CV events. A total of 113 trials were included, which used exenatide, liraglutide, lixisenatide, albiglutide, dulaglutide, and semaglutide as investigational arms. The risk of all-cause mortality and risk of $\mathrm{CV}$ mortality were lower in patients treated with a GLP-1 RA ( $p=0.015$ and $p=0.009$, respectively). No statistical difference was seen for the end points of myocardial infarction (MI), heart failure, or stroke. Four dulaglutide studies were included, which showed a lower risk of all-cause mortality $(p=0.044)$, but not a significantly reduced risk of CV mortality. Dulaglutide was the only once-weekly agent to show this benefit individually. ${ }^{19}$ In a meta-analysis of nine randomized, Phase II and III dulaglutide trials, the data of 6010 subjects were pooled, 3885 of whom received dulaglutide. A blinded adjudication committee was used to independently make determinations regarding reported events during the treatment period of each study and up to 30 days following discontinuation of treatment drugs. The primary composite end point included death due to CV cause, nonfatal MI, nonfatal stroke, or hospitalization for unstable angina and resulted in a hazard ratio of 0.57 for patients receiving dulaglutide compared to placebo or active comparator $(p=0.046)$, but no difference when the events were examined separately. ${ }^{20}$ These data are encouraging, as they support the use of dulaglutide in T2DM without the concern of increased CV risk, at least in the short term. The impact of the long-term use of dulaglutide on the risk of major CV events is currently being examined in the ongoing Researching Cardiovascular Events with a Weekly INcretin in Diabetes (REWIND) trial. ${ }^{21}$ Final data collection is estimated to be completed by July 2018, and patients will be followed for an average of 6.5 years.

Many GLP-1 RAs agents have been shown to impact patient blood pressure (BP) and heart rate (HR). ${ }^{22}$ To examine the potential impact of dulaglutide on these vital signs, 755 patients were provided with ambulatory BP monitors and were randomized to dulaglutide at either strength or placebo for 26 weeks. Patients were 56 years old on average, were taking at least one oral medication for the treatment of dia- 
betes, and had an average A1c value of 7.9\%. Dulaglutide $(0.75 \mathrm{mg})$ was non-inferior to placebo in change to 24-hour BP and HR, while dulaglutide $(1.5 \mathrm{mg})$ showed a statistically significant decrease in systolic BP of $2-3 \mathrm{mmHg}$ and a statistically significant increase in HR of $3-4 \mathrm{bpm} .^{23}$

\section{Special populations}

A post hoc examination of subjects from AWARD 1-6 trials was conducted to explore the efficacy and safety of the use of dulaglutide in Hispanic/Latino patients. Of the studies included, 3136 subjects received dulaglutide and 949 of those subjects self-identified as having Hispanic/Latino ethnicity. Baseline characteristics for subjects of Hispanic/Latino ethnicity were similar to the population at large, except that there were more female patients and the average weight was slightly lower. The percentage of Hispanic/Latino patients who achieved A1c goals, percent reduction in A1c, weight change, and AEs, including hypoglycemia, were similar to the overall population. ${ }^{24}$

Post hoc analysis of subjects who received dulaglutide in three, non-AWARD, Phase III trials conducted in Japan showed similar efficacy at 26 weeks in 855 subjects, regardless of age or BMI. Elderly patients ( $>65$ years) with a BMI of $<25 \mathrm{~kg} / \mathrm{m}^{2}$, however, were more likely to experience side effects overall than younger patients or elderly patients with a BMI of $\geq 25 \mathrm{~kg} / \mathrm{m}^{2}$, with statistically significant differences in the incidences of constipation and decrease in appetite. Subjects were predominantly male $(76 \%)$, had an average A1c value at baseline of $8.3 \%$, and all were Japanese, making generalizability of these results limited. ${ }^{25}$ When gender differences were explored in a separate analysis of two of the abovementioned Phase III studies, efficacy of dulaglutide was found to be similar, but greater weight loss (or less weight gain) was seen in female subjects, despite having a lower baseline body weight than male subjects. Females receiving dulaglutide monotherapy lost an average of $1.32 \mathrm{~kg}$, whereas males gained $0.09 \mathrm{~kg}$. When used in combination with a sulfonylurea and/or biguanide, female patients lost an average of $1.13 \mathrm{~kg}$, whereas males lost $0.21 \mathrm{~kg}$. Females experienced more AEs overall than males, and specifically experienced more nausea, constipation, and diarrhea, but there was no difference in incidences of hypoglycemia between genders. Females comprised $23 \%$ of the study population (total $n=778$ ). ${ }^{26}$

\section{Additional safety data Hypoglycemia}

In a meta-analysis of 12 Phase II and Phase III, randomized, controlled trials, dulaglutide showed a similar incidence of hypoglycemia when used as monotherapy compared to placebo, metformin, and liraglutide overall (7.8\% vs $10.6 \%$; relative risk [RR] 1.07; 95\% CI 0.80-1.44). When dulaglutide monotherapy was compared to placebo alone, the RR was 2.58 (95\% CI 1.05-6.31), but there was no significant difference detected when compared to metformin or liraglutide individually. A similar pattern was seen when dulaglutide was used as add-on therapy and compared to placebo, sitagliptin, exenatide, liraglutide, and glargine (24.5\% vs $24.5 \%$; RR 1.07 ; $95 \%$ CI 0.89-1.30). When add-on dulaglutide was compared to placebo alone, the RR of hypoglycemia was again increased (RR 1.82; 95\% CI 1.44-2.31), but as with monotherapy, there was no difference when compared to metformin. A difference was seen compared to sitagliptin $100 \mathrm{mg}$ daily with the $1.5 \mathrm{mg}$ weekly dose of dulaglutide added on (RR 2.14; CI 1.18-3.89), but not the $0.75 \mathrm{mg}$ dose. The risk of hypoglycemia was also greater with dulaglutide add-on when compared to glargine (weighted mean difference [WMD] 0.69; 95\% CI 0.56-0.85). ${ }^{27}$ When data were pooled from three Phase III studies in Japan, older patients, patients with longer-standing diabetes ( $\geq 7$ years), lower baseline body weight, and subjects with concurrent use of biguanide were all found to be more likely to experience hypoglycemia, but concurrent use of sulfonylurea (SU) was the most significant association with hypoglycemia. ${ }^{28}$ In a network meta-analysis including 30 unique studies involving onceweekly GLP-1 RAs, nine of which were dulaglutide studies, there were no significant differences found in the frequency of documented or symptomatic hypoglycemia among onceweekly GLP-1 RAs. ${ }^{29}$

\section{Acute pancreatitis}

Data from four Phase II trials and the first five AWARD trials were pooled to assess the risk of acute pancreatitis in patients treated with dulaglutide. Phase II trials ranged from 12 to 26 weeks in length, using doses of $0.1-3.0 \mathrm{mg}$, and Phase III trials ranged from 52 to 104 weeks, using only doses of 0.75 and $1.5 \mathrm{mg}$. A total of 6005 subjects were examined, 4006 of whom received dulaglutide. Comparator therapies included placebo, metformin, sitagliptin, exenatide, and insulin glargine. The resulting exposure-adjusted incidence rates of acute pancreatitis were 0.85 patients/1000 patientyears for dulaglutide, 3.52 patients/1000 patient-years for placebo, 4.71 patients/1000 patient-years for sitagliptin, and there were no events of pancreatitis in exenatide, metformin, or glargine groups. This study was limited by sample size, short duration of exposure to the study drug, and exclusion of patients with prior history of pancreatitis, but reflects a lower risk of acute pancreatitis in dulaglutide-treated individuals when compared to those receiving placebo. ${ }^{30}$ 
The data from three Phase III trials were pooled to evaluate the risk of acute pancreatitis in the Japanese population when treated with dulaglutide $(0.75 \mathrm{mg})$. Out of 917 patients who received dulaglutide, one occurrence of acute pancreatitis was determined to be drug induced, resulting in an exposureadjusted incidence rate of 2.651 patients/1000 patient-years. Elevations of amylase ( $>1 \times$ upper limit of normal [ULN] and $\geq 3 \times$ ULN) and lipase ( $\geq 3 \times$ ULN) were similar in the dulaglutide arms compared to liraglutide, insulin glargine, and placebo arms; however, lipase elevations $>1 \times$ ULN were significantly higher in the dulaglutide and liraglutide arms than in the insulin glargine and placebo arms. This analysis shares the same limitations as the previous pooled study, but is even smaller and has a maximum study duration of 52 weeks. ${ }^{31}$

\section{Neoplasms}

A total of 26 trials involving once-weekly GLP-1 RAs were examined in a meta-analysis to determine whether there was an increased risk of developing tumors of any kind with the use of dulaglutide, exenatide-ER (extended release), or albiglutide. The results indicated that there was not an increased risk of tumor development in any tissues with the use of these three agents, regardless of which agent was selected or the duration of therapy. ${ }^{32}$

\section{Comparison to other GLP-I RAs agents Efficacy}

Although there are no head-to-head trials between dulaglutide and other once-weekly agents, a network meta-analysis including 34 unique studies involving once-weekly GLP-1 RAs was conducted. Out of 34 studies, 10 included dulaglutide; additional agents examined include exenatide weekly, taspoglutide, and albiglutide. Dulaglutide (1.5 $\mathrm{mg}$ weekly) was found to have the largest mean A1c reduction compared to placebo $(-1.4 \%)$. Reduction in fasting plasma glucose (FPG) levels was highest with the use of exenatide weekly $(-2.2 \mathrm{mmol} / \mathrm{L}[\mathrm{CI}-2.6$ to $-1.8 \mathrm{mmol} / \mathrm{L}] /-39.6 \mathrm{mg} / \mathrm{dL}$ [CI -46.8 to $-32.4 \mathrm{mg} / \mathrm{dL}$ ] reduction), followed closely by dulaglutide $(1.5 \mathrm{mg})$, which showed a $-2.2 \mathrm{mmol} / \mathrm{L}(\mathrm{CI}-2.6$ to $-1.7 \mathrm{mmol} / \mathrm{L}) /-39.6 \mathrm{mg} / \mathrm{dL}(\mathrm{CI}-46.8$ to $-30.6 \mathrm{mg} / \mathrm{dL}$ ) reduction. Weight reduction was largest with the use of taspoglutide ( $20 \mathrm{mg} ;-1.3 \mathrm{~kg}$; CI -1.9 to $-0.7 \mathrm{~kg}$ ), followed by weekly exenatide and dulaglutide $(1.5 \mathrm{mg} ;-0.8 \mathrm{~kg}$; CI -1.5 to $-0.1 \mathrm{~kg}$ and $-0.8 \mathrm{~kg} ; \mathrm{CI}-1.4$ to $-0.1 \mathrm{~kg}$, respectively). ${ }^{29}$

\section{Gl side effects}

A systematic meta-analysis examining the incidence of nausea, vomiting, and diarrhea in published Phase III trials involving GLP-1 RAs showed that nausea and diarrhea were both dose-dependent side effects when subjects were treated with GLP-1 RAs, including dulaglutide. The incidence of nausea and vomiting was significantly increased in subjects taking a GLP-1 RA with metformin ( $p=0.04$ and $p=0.0009$, respectively). Long-acting agents (albiglutide, dulaglutide, exenatide weekly, and liraglutide) generally caused less nausea $(p<0.0001)$ and vomiting $(p=0.013)$, but more diarrhea ( $p=0.0013$ ) than short-acting agents (exenatide twice daily and lixisenatide) when given at the highest available dose. When compared to liraglutide daily, dulaglutide had similar RR of nausea $(p=0.74)$ and vomiting $(p=0.65)$ and a lower RR of diarrhea $(p=0.015)$. Albiglutide showed a lower RR for all the three, while exenatide weekly showed a lower risk of only nausea when compared to liraglutide. ${ }^{33}$

The aforementioned network meta-analysis examining once-weekly GLP-1 RAs also calculated odds ratio (OR) for the $\mathrm{AE}$ of nausea with use of each agent when compared to placebo. Dulaglutide (1.5 and $0.75 \mathrm{mg}$ ) showed moderate ORs (4.35 and 2.44, respectively), with less nausea occurring with use of albiglutide $(\mathrm{OR}=1.3)$ and once weekly exenitide ( $\mathrm{OR}=2.38$ ), but more nausea with use of taspoglutide $(\mathrm{OR}=6.19$ for $10 \mathrm{mg}$ strength and $\mathrm{OR}=8.32$ for $20 \mathrm{mg}$ strength). ${ }^{29}$ In a pooled analysis of three Phase III studies conducted in Japan, female patients, patients with longerstanding diabetes, lower baseline body weight, and those using concurrent SUs were all more likely to experience nausea. ${ }^{28}$

\section{Microvascular complications}

A meta-analysis was conducted to investigate the incidence of nephropathy (defined as chronic renal failure, doubling of serum creatinine ( $\mathrm{SCr}$ ), need for continuous renal replacement therapy, or macroalbuminuria) and retinopathy (defined as any $\mathrm{AE}$ reported as "retinopathy," retinal photocoagulation, treatment with intravitreal agents, macular edema, vitreous hemorrhage, retinal detachment, or the onset of diabetes-related blindness) in subjects receiving a GLP-1 RA. Investigators found that, as a class, there was no increased or decreased risk overall for either retinopathy or nephropathy; however, semaglutide was associated with a lower OR for nephropathy, and a higher OR for retinopathy (based on only one study). Liraglutide was associated with a lower risk of retinopathy, while dulaglutide reflected no increased or decreased risk for either microvascular complication. ${ }^{34} \mathrm{~A}$ subsequent publication investigating renal outcomes in participants of the LEADER trial found that there were fewer instances of new-onset macroalbuminuria in subjects in the liraglutide arm compared to placebo (hazard ratio $0.74 ; p=0.0004$ ) after a median follow-up of 3.84 years. 
The same study also showed a decreased occurrence of the composite renal outcome (which consisted of new-onset, persistent macroalbuminuria, persistent doubling of the $\mathrm{SCr}$ and an estimated glomerular filtration rate [eGFR] $\leq 45 \mathrm{~mL} /$ $\min / 1.73 \mathrm{~m}^{2}$, need for continuous renal replacement therapy with no reversible cause of renal disease, or death from renal disease) in the liraglutide arm (hazard ratio $0.78 ; p=0.003) .{ }^{35}$

\section{Prediction of therapeutic response}

Post hoc analysis of the AWARD-1 and AWARD-5 trial data for patients in the dulaglutide arms showed a strong association between lower fasting blood glucose (FBG) levels at week $2(<142.2 \mathrm{mg} / \mathrm{dL}$ or $<7.9 \mathrm{mmol} / \mathrm{L})$ and glycemic response at week 26, which was significant for both strengths of dulaglutide. Glycemic response was defined as either 1) achievement of A $1 \mathrm{c}<7 \%, 2$ ) A $1 \mathrm{c}$ reduction of $>0.8 \%$ if baseline was $<8 \%$, 3) A 1 c reduction of $>1.1 \%$ if baseline was $\geq 8 \%$ and $<9 \%$, or 4) A1c reduction $>1.6 \%$ if baseline was $\geq 9 \% .{ }^{36}$ This may allow for the use of FBG values at week 2 as a predictor of future therapy response, although data did not show an association between high FBG at week 2 and therapy failure.

Data from the first six AWARD trials were pooled to examine baseline characteristics for potential predictors of therapeutic response to dulaglutide treatment at week 26. The primary factor associated with a greater reduction in A1c $(-0.594 \%$ additional; $p<0.0001)$ in the 2806 patients studied was higher baseline A1c. To a much lesser extent, associations were seen between the age group of $\leq 65$ years, fasting serum insulin of $\leq 55 \mathrm{pmol} / \mathrm{L}(\leq 7.92 \mathrm{mIU} / \mathrm{L})$ or eGFR of $\leq 100 \mathrm{~mL} / \mathrm{min} / 1.73 \mathrm{~m}^{2}$, and additional A1c lowering of $-0.175(p=0.003),-0.197(p<0.0001)$, and $-0.143(p=0.002)$, respectively. Subjects with lower fasting serum glucose (FSG) exhibited less A1c lowering $(+0.0468 ; p<0.0001)$ than those with higher FSG values at baseline. ${ }^{37}$ When data were pooled from the three Phase III trials conducted in Japan, a similar associate was seen between higher A1c and greater response to dulaglutide in A1c lowering; however, subjects with a lower baseline body weight ( $<70 \mathrm{~kg}$ ), lower BMI $\left(<25 \mathrm{~kg} / \mathrm{m}^{2}\right)$, and higher age ( $\geq 65$ years) were also likely to experience greater A1c lowering. Patients with a lower baseline A1c were more likely to achieve an A1c goal of $<7 \%$. Female subjects, those with lower body weight, higher A1c, and concurrent biguanide therapy tended to lose more weight on dulaglutide. ${ }^{28}$ These results suggest that patients in the general population with poorly controlled T2DM are likely to achieve greater A1c lowering than those who are closer to their glycemic goals, and that some Japanese patients may have additional factors that are associated with a stronger response to dulaglutide therapy.

\section{Patient perspective}

Treatment satisfaction over 52 weeks was examined in subjects from the AWARD-1 and AWARD-3 trials using the Diabetes Treatment Satisfaction Questionnaire, status version (DTSQs) and change version (DTSQc). DTSQs scores were significantly improved at 26 weeks in subjects given dulaglutide (at either strength) when compared to placebo or exenatide, a pattern which persisted at 52 weeks when dulaglutide was compared to exenatide. Subjects on exenatide reported lesser improvement in perceived hyperglycemia compared to subjects receiving dulaglutide, as well as an increase in perceived frequency of hypoglycemia at 26 and 52 weeks. There were no significant differences in DTSQs scores between dulaglutide arms and the metformin arm in AWARD-3, but dulaglutide patients showed a greater improvement in perceived hyperglycemia at 52 weeks. ${ }^{38}$

Additional patient-reported outcome (PRO) questionnaires were used in other AWARD trials. The Ability to Perform Physical Activities of Daily Living (APPADL) and Impact of Weight on Self-Perception (IW-SP) were administered to AWARD-1, AWARD-2, AWARD-3, AWARD-4, and AWARD-6 subjects. Dulaglutide arms showed no significant difference in the APPADL scores when compared to metformin, exenatide, or liraglutide at 26 weeks, which persisted at week 52 for metformin and exenatide comparators. When compared to insulin glargine, results were conflicting. AWARD-2 showed a significantly higher APPADL score for both strengths of dulaglutide compared to glargine at week 52 , but at 78 weeks, this difference only persisted for the $1.5 \mathrm{mg}$ dose. In AWARD-4, however, no significant differences in APPADL scores were seen with either strength of dulaglutide when compared to glargine use at 26 or 52 weeks. IW-SP scores were significantly higher in the dulaglutide $1.5 \mathrm{mg}$ group compared to insulin glargine in AWARD-4 (at 26 and 52 weeks) and AWARD-2 (at 78 weeks), but there was no difference when compared to metformin, exenatide, or liraglutide. The Impact of Weight on Quality of Life-Lite (IWQOL-Lite) was administered to AWARD-5 subjects only and showed a significantly higher scoring in the dulaglutide $1.5 \mathrm{mg}$ group compared to sitagliptin at 104 weeks. The Adult Low Blood Sugar Survey (ALBSS) was administered to AWARD-2 and AWARD-4 subjects, but no difference was seen in scores in AWARD-4, while AWARD-2 showed a significantly larger improvement in score in both dulaglutide groups at weeks 52 and 78, including the separate worry and behavior components. ${ }^{39}$

Patients from two other Phase III trials were given the Perceptions about Medications-Diabetes 21 Questionnaire - Japanese 
version (PAM-D21-J) and the Injectable Diabetes Medication Questionnaire - Japanese version (IDMQ-J) at week 26 in each study. Patients in these studies were exclusively Japanese and $>70 \%$ were male, with an average age of 57 years and an A1c value of $8 \%$. Scores for dulaglutide $(0.75 \mathrm{mg}$ weekly) in the area of perceived convenience and flexibility were significantly higher than liraglutide ( $0.9 \mathrm{mg}$ daily), insulin glargine (daily), or placebo; scores for perceived effectiveness and emotional effects were also higher for dulaglutide than glargine or placebo, with no statistically significant difference in perceived physical effects. Higher satisfaction was reported by dulaglutide subjects compared to all other therapies studied. Dulaglutide also scored higher than placebo in ease of use, lifestyle impact, and blood glucose control and higher than glargine in blood glucose control. PRO questionnaires were considered exploratory in this evaluation, as neither were psychometrically validated. ${ }^{40} \mathrm{It}$ is likely that the better performance overall of dulaglutide on both PROs is driven by its once-weekly administration; however, patients on placebo injections were only required to administer weekly and yet dulaglutide still consistently outperformed placebo with both tools. Of note, PRO studies used prefilled syringes to administer dulaglutide, rather than the commercially available single-use pen, which would likely improve ease of use even further.

\section{Discussion}

Phase III studies have demonstrated comparable or superior efficacy of dulaglutide to several therapeutic options in T2DM. As a result, dulaglutide presents a reasonable therapeutic selection for the escalation of therapy in patients maintained on oral therapy as well as those already initiated on basal insulin. In comparison to alternative GLP-1 agonists, dulaglutide has demonstrated superior A1c reduction vs liraglutide and exenatide. Multiple Phase III studies have shown the effectiveness of dulaglutide as second- or thirdline therapy in addition to oral hypoglycemic agents, which supports current guideline recommendations for place in therapy of GLP-1 agonists. ${ }^{41}$ There are additional Phase III data that support the efficacy of dulaglutide when added to basal insulin, specifically in comparison to placebo; therefore, further study vs an active comparator in the role of escalation of injectable therapy would provide useful insights into appropriate patient selection. Regardless, current evidence does establish dulaglutide as a reasonable therapeutic option in addition to basal insulin.

The 2018 American Diabetes Association (ADA) Standards of Medical Care in diabetes have placed particular focus on the initiation of second-line hypoglycemic agents with proven $\mathrm{CV}$ benefits for patients with a history atherosclerotic CV disease. ${ }^{41}$ At this time, the only GLP-1 agonist to carry an FDA indication for the reduction in the risk of major CV events is liraglutide. This is based on results of the LEADER trial, which demonstrated a hazard ratio of $0.87 ; 95 \%$ CI $0.78-0.97, p<0.01$, for superiority for the primary outcome of first occurrence of death from CV causes, nonfatal MI, or nonfatal stroke. ${ }^{42}$ The newly approved GLP-1 agonist, semaglutide, also demonstrated a significant reduction at the primary outcome of the first occurrence of CV death, nonfatal MI, or nonfatal stroke in SUSTAIN-6. This was driven by a reduction in the incidence of nonfatal stroke, which was the only outcome to demonstrate a significant reduction when analyzed separately. It is, however, notable that SUSTAIN-6 was designed as a non-inferiority trial without a prespecified superiority analysis, and the median follow-up was 2.1 years, representing a relatively short study duration. ${ }^{43}$ The recently published EXSCEL trial evaluated the CV outcomes of treatment with once-weekly exenatide and found no significant difference in major $\mathrm{CV}$ events when compared to placebo. ${ }^{44}$ Outside of the class of GLP-1 agonists, separate studies examining the use of empagliflozin and canagliflozin in patients with T2DM and high $\mathrm{CV}$ risk showed a reduction in the composite end point of death from CV cause, nonfatal MI, and nonfatal stroke compared to placebo. ${ }^{45,46}$ While some evidence has supported a reduction in overall mortality with dulaglutide, the currently available data have not demonstrated an advantage associated with dulaglutide in terms of $\mathrm{CV}$ outcomes. ${ }^{19}$ The findings of the ongoing REWIND trial will further define the impact of dulaglutide on CV outcomes, as well as provide insights into whether reduction in $\mathrm{CV}$ outcomes may be a class effect of GLP-1 agonists.

Overall, data have demonstrated acceptable tolerability and safety of dulaglutide. Rates of hypoglycemia do not appear to differ significantly from other once-weekly GLP-1 agonists. ${ }^{29}$ Pooled data have not demonstrated a significant increase in the risk of pancreatitis compared to placebo; however, the available literature has a number of limitations. ${ }^{30}$ Likewise, compiled data to date have not supported an increased risk of neoplasm with the use of dulaglutide. ${ }^{32}$ GI AEs present a commonly encountered reason for the discontinuation of GLP-1 agonists. Long-acting GLP-1 agonists, excluding taspoglutide, have demonstrated less nausea and vomiting than short-acting GLP-1 agonists. ${ }^{33}$ In comparison to other long-acting agents, dulaglutide has demonstrated a similar risk of nausea compared to liraglutide, but a greater risk of nausea compared to albiglutide and once-weekly exenatide. ${ }^{29,33}$ The available data do not establish an impact of dulaglutide on microvascular complications. ${ }^{34}$ 
Patient-specific factors that may alter the impact of dulaglutide include female gender (greater weight loss, higher risk of AEs) and elderly patients (>65 years) with normal BMI (higher risk of experiencing side effects). ${ }^{25,26}$ These patterns, however, were seen during ad hoc analyses of studies including only Japanese patients, requiring additional investigation to determine whether they exist in other populations. In the broader population, higher A1c upon initiation and lower FBG values after 2 weeks of therapy may be useful predictors of therapeutic response to dulaglutide. ${ }^{37}$

In terms of the assessment of patient perspective, PRO questionnaires overall indicate that patient perceptions of various quality of life markers with the use of dulaglutide are, at a minimum, equivalent to mainstays of therapy, and in some instances, there is a perceived improvement with dulaglutide use. ${ }^{38-40}$

\section{Conclusion}

Dulaglutide represents a well-tolerated and efficacious option in the treatment of T2DM. Ongoing trial data will better inform the future place in the therapy of dulaglutide considering the recent guideline emphasis on agents with beneficial effects on $\mathrm{CV}$ outcomes.

\section{Acknowledgment}

The authors would like to acknowledge Palak Desai, Van Kieu, Kelli Shiroma, and Vincent Mach, PharmD candidates 2018, for their role in drafting article summaries.

\section{Disclosure}

The authors report no conflicts of interest in this work.

\section{References}

1. Barrington P, Chien JY, Showalter HDH, et al. A 5-week study of the pharmacokinetics and pharmacodynamics of LY2189265, a novel, long-acting glucagon-like peptide-1 analogue, in patients with type 2 diabetes. Diabetes Obes Metab. 2011;13(5):426-433.

2. Gurung T, Shyangdan DS, O'Hare JP, Waugh N. A novel, long-acting glucagon-like peptide receptor-agonist: dulaglutide. Diabetes Metab Syndr Obes. 2015;8:363-386.

3. Jendle J, Grunberger G, Blevins T, Giorgino F, Hietpas RT, Botros FT. Efficacy and safety of dulaglutide in the treatment of type 2 diabetes: a comprehensive review of the dulaglutide clinical data focusing on the AWARD phase 3 clinical trial program. Diabetes Metab Res Rev. 2016;32(8):776-790.

4. Thompson AM, Trujillo JM. Advances in the treatment of type 2 diabetes: impact of dulaglutide. Diabetes Metab Syndr Obes. 2016;9:125-136.

5. Scheen AJ. Dulaglutide for the treatment of type 2 diabetes. Expert Opin Biol Ther. 2017;17(4):485-496.

6. Trulicity (dulaglutide) injection, solution [prescribing information] Indianapolis, IN: Eli Lilly and Company; 2017.

7. Trulicity (dulaglutide) injection, solution [medication guide] Indianapolis, IN: Eli Lilly and Company; 2017.
8. Umpierrez G, Tofe Povedano S, Perez Manghi F, Shurzinske L, Pechtner $\mathrm{V}$. Efficacy and safety of dulaglutide monotherapy versus metformin in type 2 diabetes in a randomized controlled trial (AWARD-3). Diabetes Care. 2014;37(8):2168-2176.

9. Weinstock RS, Guerci B, Umpierrez G, Nauck MA, Skrivanek Z, Milicevic Z. Safety and efficacy of once-weekly dulaglutide versus sitagliptin after 2 years in metformin-treated patients with type 2 diabetes (AWARD-5): a randomized, phase III study. Diabetes Obes Metab. 2015;17(9):849-858.

10 Emoto M, Terauchi Y, Ozeki A, Oura T, Takeuchi M, Imaoka T. A 1-year safety study of dulaglutide in Japanese patients with type 2 diabetes on a single oral hypoglycemic agent: an open-label, nonrandomized, phase 3 trial. Endocr J. 2015;62(12):1101-1114.

11. Wysham C, Blevins T, Arakaki R, et al. Efficacy and safety of dulaglutide added onto pioglitazone and metformin versus exenatide in type 2 diabetes in a randomized controlled trial (AWARD-1). Diabetes Care. 2014;37(8):2159-2167.

12. Dungan KM, Povedano ST, Forst T, et al. Once-weekly dulaglutide versus once-daily liraglutide in metformin-treated patients with type 2 diabetes (AWARD-6): a randomised, open-label, phase 3, non-inferiority trial. Lancet. 2014;384(9951):1349-1357.

13. Odawara M, Miyagawa J, Iwamoto N, Takita Y, Imaoka T, Takamura T. Once-weekly glucagon-like peptide-1 receptor agonist dulaglutide significantly decreases glycated haemoglobin compared with oncedaily liraglutide in Japanese patients with type 2 diabetes: 52 weeks of treatment in a randomized phase III study. Diabetes Obes Metab. 2016;18(3):249-257.

14. Giorgino F, Benroubi M, Sun JH, Zimmermann AG, Pechtner V. Efficacy and safety of once-weekly dulaglutide versus insulin glargine in patients with type 2 diabetes on metformin and glimepiride (AWARD-2). Diabetes Care. 2015;38(12):2241-2249.

15. Blonde L, Jendle J, Gross J, et al. Once-weekly dulaglutide versus bedtime insulin glargine, both in combination with prandial insulin lispro, in patients with type 2 diabetes (AWARD-4): a randomised, open-label, phase 3, non-inferiority study. Lancet. 2015;385(9982):2057-2066.

16. Araki E, Inagaki N, Tanizawa Y, Oura T, Takeuchi M, Imaoka T. Efficacy and safety of once-weekly dulaglutide in combination with sulphonylurea and/or biguanide compared with once-daily insulin glargine in Japanese patients with type 2 diabetes: a randomized, open-label, phase III, non-inferiority study. Diabetes Obes Metab. 2015;17(10):994-1002.

17. Pozzilli P, Norwood P, Jodar E, et al. Placebo-controlled, randomized trial of the addition of once-weekly glucagon-like peptide-1 receptor agonist dulaglutide to titrated daily insulin glargine in patients with type 2 diabetes (AWARD-9). Diabetes Obes Metab. 2017;19(7):1024-1031.

18. Dungan KM, Weitgasser R, Perez Manghi F, et al. A 24-week study to evaluate the efficacy and safety of once-weekly dulaglutide added on to glimepiride in type 2 diabetes (AWARD-8). Diabetes Obes Metab. 2016;18(5):475-482.

19. Monami M, Zannoni S, Pala L, et al. Effects of glucagon-like peptide-1 receptor agonists on mortality and cardiovascular events: a comprehensive meta-analysis of randomized controlled trials. Int $J$ Cardiol. 2017;240:414-421.

20. Ferdinand KC, Botros FT, Atisso CM, Sager PT. Cardiovascular safety for once-weekly dulaglutide in type 2 diabetes: a pre-specified metaanalysis of prospectively adjudicated cardiovascular events. Cardiovasc Diabetol. 2016;15(1):38.

21. Eli Lilly and Company. Researching cardiovascular events with a weekly incretin in diabetes (REWIND). Bethesda, MD: National Library of Medicine; 2011-2013. Available from: clinicaltrials.gov. NLM Identifier: NCT01394952. Accessed March 22, 2018.

22. Sun F, Wu S, Guo S, et al. Impact of GLP-1 receptor agonists on blood pressure, heart rate and hypertension among patients with type 2 diabetes: a systematic review and network meta-analysis. Diabetes Res Clin Pract. 2015;110(1):26-37.

23. Ferdinand KC, White WB, Calhoun DA, et al. Effects of the once-weekly glucagon-like peptide-1 receptor agonist dulaglutide on ambulatory blood pressure and heart rate in patients with type 2 diabetes mellitus. Hypertension. 2014;64(4):731-737. 
24. Davidson JA, Manghi FP, Yu M, Linetzky B, Lando LF. Efficacy and safety of dulaglutide in Hispanic/Latino patients with type 2 diabetes in the AWARD clinical program. Endocr Pract. 2016;22(12):1406-1414.

25. Hamano K, Nishiyama H, Matsui A, Sato M, Takeuchi M. Efficacy and safety analyses across 4 subgroups combining low and high age and body mass index groups in Japanese phase 3 studies of dulaglutide 0.75 mg after 26 weeks of treatment. Endocr J. 2017;64(4):449-456.

26. Onishi Y, Oura T, Matsui A, Matsuura J, Iwamoto N. Analysis of efficacy and safety of dulaglutide $0.75 \mathrm{mg}$ stratified by sex in patients with type 2 diabetes in 2 randomized, controlled phase 3 studies in Japan. Endocr J. 2017;64(5):553-560.

27. Zhang L, Zhang M, Zhang Y, Tong N. Efficacy and safety of dulaglutide in patients with type 2 diabetes: a meta-analysis and systematic review. Sci Rep. 2016;6:18904.

28. Onishi Y, Oura T, Nishiyama H, Ohyama S, Takeuchi M, Iwamoto N. Subgroup analysis of phase 3 studies of dulaglutide in Japanese patients with type 2 diabetes. Endocr J. 2016;63(3):263-273.

29. Zaccardi F, Htike ZZ, Webb DR, Khunti K, Davies MJ. Benefits and harms of once-weekly glucagon-like peptide-1 receptor agonist treatments: a systematic review and network meta-analysis. Ann Intern Med. 2016;164(2):102-113.

30. Nauck MA, Frossard JL, Barkin JS, et al. Assessment of pancreas safety in the development program of once-weekly GLP-1 receptor agonist dulaglutide. Diabetes Care. 2017;40(5):647-654.

31. Emoto M, Oura T, Matsui A, Kazama H, Iwamoto N. Pancreatic safety in Japanese patients with type 2 diabetes treated with once weekly dulaglutide $0.75 \mathrm{mg}$ up to 52 weeks in phase 3 clinical trials. Endocr J. 2017;64(2): 191-206.

32. Guo X, Yang Q, Dong J, Liao L, Zhang W, Liu F. Tumour risk with once-weekly glucagon-like peptide-1 receptor agonists in type 2 diabetes mellitus patients: a systematic review. Clin Drug Investig. 2016;36(6):433-441.

33. Bettge K, Kahle M, Abd El Aziz MS, Meier JJ, Nauck MA. Occurrence of nausea, vomiting and diarrhoea reported as adverse events in clinical trials studying glucagon-like peptide-1 receptor agonists: a systematic analysis of published clinical trials. Diabetes Obes Metab. 2017;19(3):336-347.

34. Dicembrini I, Nreu B, Scatena A, et al. Microvascular effects of glucagon-like peptide-1 receptor agonists in type 2 diabetes: a meta-analysis of randomized controlled trials. Acta Diabetol. 2017;54(10):933-941.
35. Mann JFE, Orsted DD, Buse JB. Liraglutide and renal outcomes in type 2 diabetes. N Engl J Med. 2017;377(22):2197-2198.

36. Grunberger G, Forst T, Fernandez Lando L, et al. Early fasting glucose measurements can predict later glycaemic response to once weekly dulaglutide. Diabet Med. 2016;33(3):391-394.

37. Wysham C, Guerci B, D’Alessio D, Jia N, Botros FT. Baseline factors associated with glycaemic response to treatment with once-weekly dulaglutide in patients with type 2 diabetes. Diabetes Obes Metab. 2016;18(11): 1138-1142.

38. Reaney M, Yu M, Lakshmanan M, Pechtner V, van Brunt K. Treatment satisfaction in people with type 2 diabetes mellitus treated with onceweekly dulaglutide: data from the AWARD-1 and AWARD-3 clinical trials. Diabetes Obes Metab. 2015;17(9):896-903.

39. Yu M, Van Brunt K, Varnado OJ, Boye KS. Patient-reported outcome results in patients with type 2 diabetes treated with once-weekly dulaglutide: data from the AWARD phase III clinical trial programme. Diabetes Obes Metab. 2016;18(4):419-424.

40. Suzuki S, Oura T, Takeuchi M, Boye KS. Evaluation of the impact of once weekly dulaglutide on patient-reported outcomes in Japanese patients with type 2 diabetes: comparisons with liraglutide, insulin glargine, and placebo in two randomized studies. Health Qual Life Outcomes. 2017;15(1):123.

41. American Diabetes Association. Pharmacologic approaches to glycemic treatment: standards of medical care in diabetes -2018. Diabetes Care. 2018;41(suppl 1):S73-S85.

42. Marso SP, Daniels GH, Brown-Frandsen K, et al. Liraglutide and cardiovascular outcomes in type 2 diabetes. $N$ Engl JMed. 2016;375(4):311-322.

43. Marso SP, Bain SC, Consoli A, et al. Semaglutide and cardiovascular outcomes in patients with type 2 diabetes. NEngl J Med. 2016;375(19): 1834-1844.

44. Holman RR, Bethel MA, Mentz RJ, et al. Effects of once-weekly exenatide on cardiovascular outcomes in type 2 diabetes. NEngl JMed. 2017;377(13): $1228-1239$.

45. Zinman B, Wanner C, Lachin JM, et al. Empagliflozin, cardiovascular outcomes, and mortality in type 2 diabetes. N Engl J Med. 2015;373(22): 2117-2128

46. Neal B, Perkovic V, Matthews DR. Canagliflozin and cardiovascular and renal events in type 2 diabetes. N Engl J Med. 2017;377(21):644-657.

47. Trulicity (dulaglutide) injection, solution [instructions for use] Indianapolis, IN: Eli Lilly and Company; 2016.

Diabetes, Metabolic Syndrome and Obesity: Targets and Therapy

Dovepress

\section{Publish your work in this journal}

Diabetes, Metabolic Syndrome and Obesity: Targets and Therapy is an international, peer-reviewed open-access journal committed to the rapid publication of the latest laboratory and clinical findings in the fields of diabetes, metabolic syndrome and obesity research Original research, review, case reports, hypothesis formation, expert opinion and commentaries are all considered for publication. The manuscript management system is completely online and includes a very quick and fair peer-review system, which is all easy to use. Visit http://www.dovepress.com/testimonials.php to read real quotes from published authors. 